\title{
TRANSIENT ANALYSIS OF AN IVHM GRAPPLE IMPACT TTEST
}

By R. G. Hill

Hanford Engineering Development Laboratory

SUMMARY

A lumped-mass model has been used to represent the impact condition between a fuel duct and an IVHM (In-Vessel Fuel Handling Machine). The nonlinear effects of a Bellville spring and the free fall impact of the fuel duct on the IVHM were included. The purpose of the tests was to determine the loads on the fuel duct due to the impact. A comparison between experimental and theoretical results is presented.

\section{INTRODUCTION}

In the operation of the FTR (Fast Test Reactor) an IVHM is used to handle core components under various component and core conditions. The component under consideration is a fuel duct which interfaces with the IVHM by means of a grapple mechanism. The grapple grips a nozzle-handling socket mounted on the end of the fuel duct. Under certain operating conditions the fuel duct drops a short distance to impact on the grapple fingers. A simulated mechanical mockup of the FTR core and the IVHM was set up, and IVHM fuel duct withdrawal and insertion tests were conducted. During these tests high accelerations were measured on the simulated fuel duct. The experimental data indicated that the acceleration loads were due to the impact of the fuel duct on the grapple. This paper describes how the results of the analysis and tests of the impact are interpreted in terms of the response of the simulated fuel duct and the IVHM structure.

SYMBOLS

$\begin{array}{ll}\text { a } & \text { acceleration } \\ \text { B } & \text { scalar damper } \\ \text { d } & \text { drop distance } \\ \text { g } & \text { structural damping } \\ t & \text { time }\end{array}$

DESCRIPTION OF IVHM

The FFTF (Fast. FIux Test Facility) simulated core test facility and an IVHM positioned for fuel duct insertion are shown in figure 1 . The IVHM consists of a motor-driven mechanism mounted on a lead screw and a grapple assembly as shown in figures 1 to 3. Four fuel duct support fingers (fig. 3) support the weight of the fuel duct during insertion and provide for the withdrawal forces. The IVHM is used to transfer fuel duct components from the 
active core to fixed storage positions located outside the core region. Fuel handling problems can occur due to distortion of the individual fuel ducts and the core. The distortion effects can be induced by stainless steel swelling and thermal creep (ref. 1). Twelve core restraint yokes located hexagonally at two levels maintain the lateral position and compactness of the core.

\section{Free Fall Condition}

There are two operating conditions of the IVHM that have been investigated in this report. The first is a free fall impact of the fuel duct on the grapple and, secondly, a free fall impact combined with an initial condition of pre-load on the IVHM and fuel duct. During the insertion of the fuel duct, the above core load pad contacts the core (fig. 1), and a gap exists between the fingers on the grapple and the fuel duct. The core restraint yokes are retracted, the respective fuel duct position opens and the fuel duct drops the gap distance to impact on the grapple support fingers.

\section{Pre-Load Conditions}

Certain core conditions (ref. 1) require that a compressive force be applied to the fuel duct for insertion. The lead screw on the IVHM is used to apply the compressive force through the grapple (turnbuckle effect) to the fuel duct. Again, as the grapple engages the top of the fuel duct for the compressive load a gap exists between the grapple fingers and the nozzle-handling socket on the fuel duct.

When insertion occurs the fuel duct experiences a free fall with an initial condition of pre-load. The compressive pre-load (turnbuckle effect) is relieved on both the fuel duct and the IVHM during the first milliseconds of fuel duct free fall. The fuel duct then impacts on the grapple support fingers. The load cell oscillogram indicated that the $1000 \mathrm{Ib}$ pre-load initial condition was a ramp function with a time duration of 0.026 second. The effect of the pre-load on the initial acceleration of the fuel duct is unknown. Due to the manner in which the accelerations were recorded, the change in free fall time due to the pre-load could not be determined.

\section{LUMPED-MASS MODEL}

Basic Model

After a review of the test facility and test data, it was decided to use a relatively simple model to represent the IVHM and fuel duct so that the results of the analysis would be available quickly. The physical properties used in the model in most cases were calculated from the results of load deflection and other tests on the simulated IVHM. Figure 4 shows the scalar elements that were chosen to represent the stiffnesses, masses, and damping properties of the IVHM and the fuel duct. The IVHM and fuel duct were idealized with six degrees of freedom with instrumentation locations and areas of nonlinear response considered in the selection of grid points and lumped masses. The scalar damper values shown in the NASTRAN Input (fig. 5) were calculated from the frequency and measured structural damping values (see ref. 2 for equation). A structural 
damping value ( $\mathrm{g}=15$ percent) was calculated for the assembled IVHM by considering the rate of decay and of successive rebounds of the fuel duct on grapple support fingers, as shown by the IVHM load cell oscillogram (fig. 6). A structural damping value of $g=2$ percent was calculated for fuel duct. The fuel duct was empty. except for a lead weight mounted in bottom of the duct to simulate the components of the fuel duct.

\section{Nonlinear Considerations}

Two nonlinear conditions were considered in the model shown in figure 4, a Bellville spring with stiffness different in tension than in compression, Element 4, and the free fall gap, Element 5. For these conditions the nonlinear provision of NASTRAN was used. The nonlinear effects were treated through the use of an additional applied load vector and by means of a transfer function, the NONLIN 1 and TF input cards. (See figure 5 for NASTRAN input.) To use the nonlinear provision requires rigid format 9, Direct Transient Response. In this format (ref. 3) numerical integration of the coupled equations is achieved by employing a central difference equivalent step-by-step procedure. It was found that the solution became unstable as the time step was increased or as the value of the lumped masses was reduced. The stability problem was evident through large and/or plus or minus oscillating displacements. A discussion of the stability problems described here is found in appendix $\mathrm{C}$ of reference 4.

\section{COMPARISON OF RESULTS}

Results from the lumped-mass model for displacement, force, and acceleration parameters are shown in figure 7 to figure 12 for the $1 \frac{5}{16}$ in. and $1 \frac{3}{8}$ in. free fall conditions. On the two displacement curves (figs. 7 and 10) the theoretical free fall times $\left(d=\frac{1}{2} a t^{2}\right)$ for the $1 \frac{5}{16}$ in. and $1 \frac{3}{8}$ in. gap distances are shown. The theoretical time for a single mass provides a close approximation of the free fall time of the two degree of freedom fuel duct model. The peak displacement and acceleration did not occur at first time of impact. This is shown by both the NASTRAN and experimental results and is due to the response of the multidegree of freedom system (figs. 6, 7, and 10).

A comparison of the wave forms between the experimental and NASTRAN results for the IVHM load cell (figs. 6 and 8 ) indicates that structural damping is larger than the 15 percent value used in the lumped-mass model. The structural damping ( $g=15$ percent) was determined from the rate of decay of successive rebound.s. It was difficult to determine a consistent damping parameter after the impact event from the load cell oscillogram.

It was found from the NASTRAN results that structural damping had a very small effect on the amplitude of the first impact event. However, the value of structural damping made a significant change in the response of the IVHM subsequent to the first impact. Structural damping was varied from 0 to 15 percent. 
The response of the IVHM due to the initial condition of the $1000 \mathrm{Ib}$ preload is shown in figure 11. The pre-load was input to the model at Grid Point 4 as a ramp function with a time duration of 0.026 second. No pre-load was applied to the fuel duct Grid Point 5 for the reasons previously noted in this report. Nominally, the free fall time could be expected to be less than the theoretical time because of the increase in acceleration of the fuel duct. (See fig. 10.) Nevertheless the response characteristics shown in figures 9, 10, and 12 yield an approximation of the effect of the pre-load condition on the IVHM.

Figures 9 and 12 show the acceleration response of the fuel duct and the IVHM. The bounce effect, due to the multi-degree of freedom response, and the successive rebounds are illustrated. In both instances, the $1 \frac{5}{16} \mathrm{in}$. and $1 \frac{3}{8}$ in. free falls, the accelerations on the IVHM are higher than on the fuel duct.

A comparison ( $f i g .13$ ) is made of the experimental and NASTRAN results for the accelerometer on the top of the fuel duct and the IVHM load cell. The effect of the pre-load is to reduce the amplitude of acceleration on the fuel duct but to increase it on the IVHM. (See figs. 9 and 12.)

\section{CONCLUDING REMARKS}

The experience gained in the application of NASTRAIV to a complex reactor component impact condition has been presented.

Comparison of the results obtained with NASTRAN with results from the experiments and theory shows NASTRAN to be very effective in calculating the transient response of the IVHM and fuel duct.

The fuel duct loads determined by these tests and analyses should be considered qualitative. The simulated fuel duct has different dynamic properties than the prototype FTR fuel duct. The two mass models of the fuel duct should be extended to include the principal dynamic characteristics of the components of the FTR fuel duct.

\section{REFERENCES}

1. Waymire, G. R.: The Significance of Applied Mechanics In Designing the Fast Test Reactor. Nuclear Engineering and Design, vol. 19, no. 1, Apr. 1972.

2. Tong, K. N.: Theory of Mechanical Vibration. John Wiley \& Sons, Inc., 1960.

3. MacNeal, R. K.: The NASTRAN Theoretical Manual. NASA SP-221, Oct. 1969.

4. Peterson, I.: SADSAM User's Manual. MSR-10, Dec. 1970. 
FIGURE 1. FFTF SIMULATED CORE AND IVHM

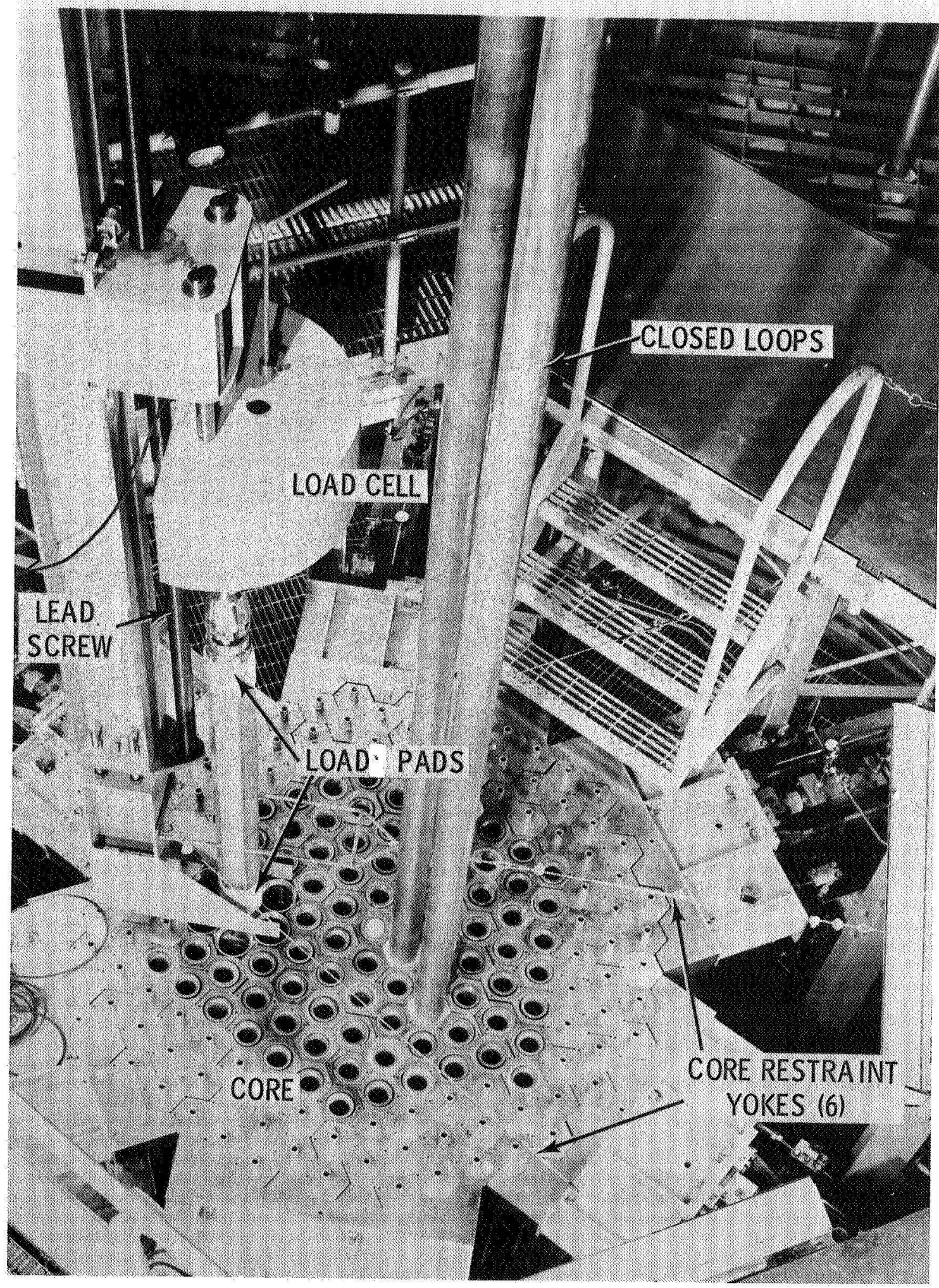


FIGURE 2. SIMULATED GRAPPLE AND FUEL DUCT ASSEMBLY

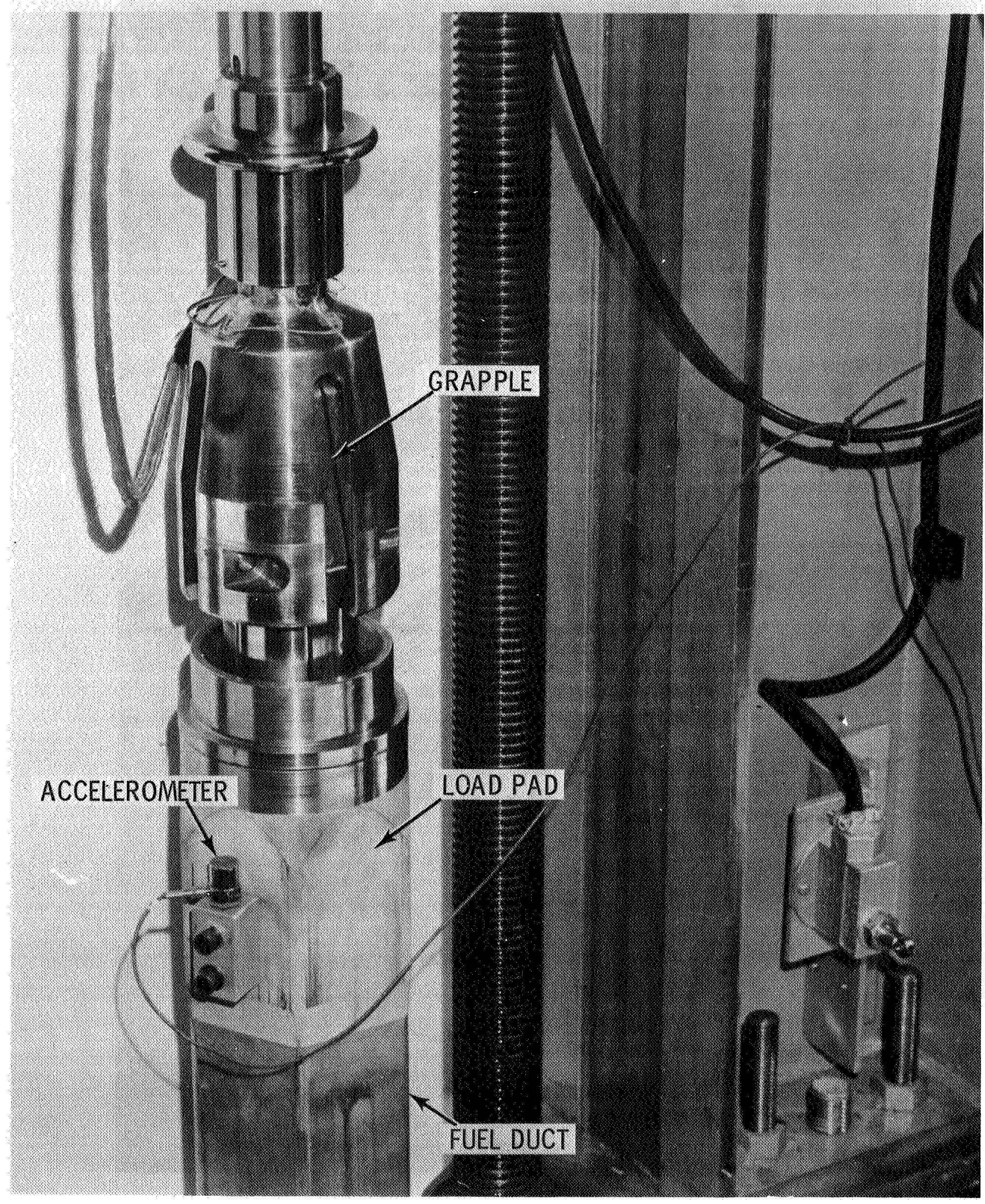




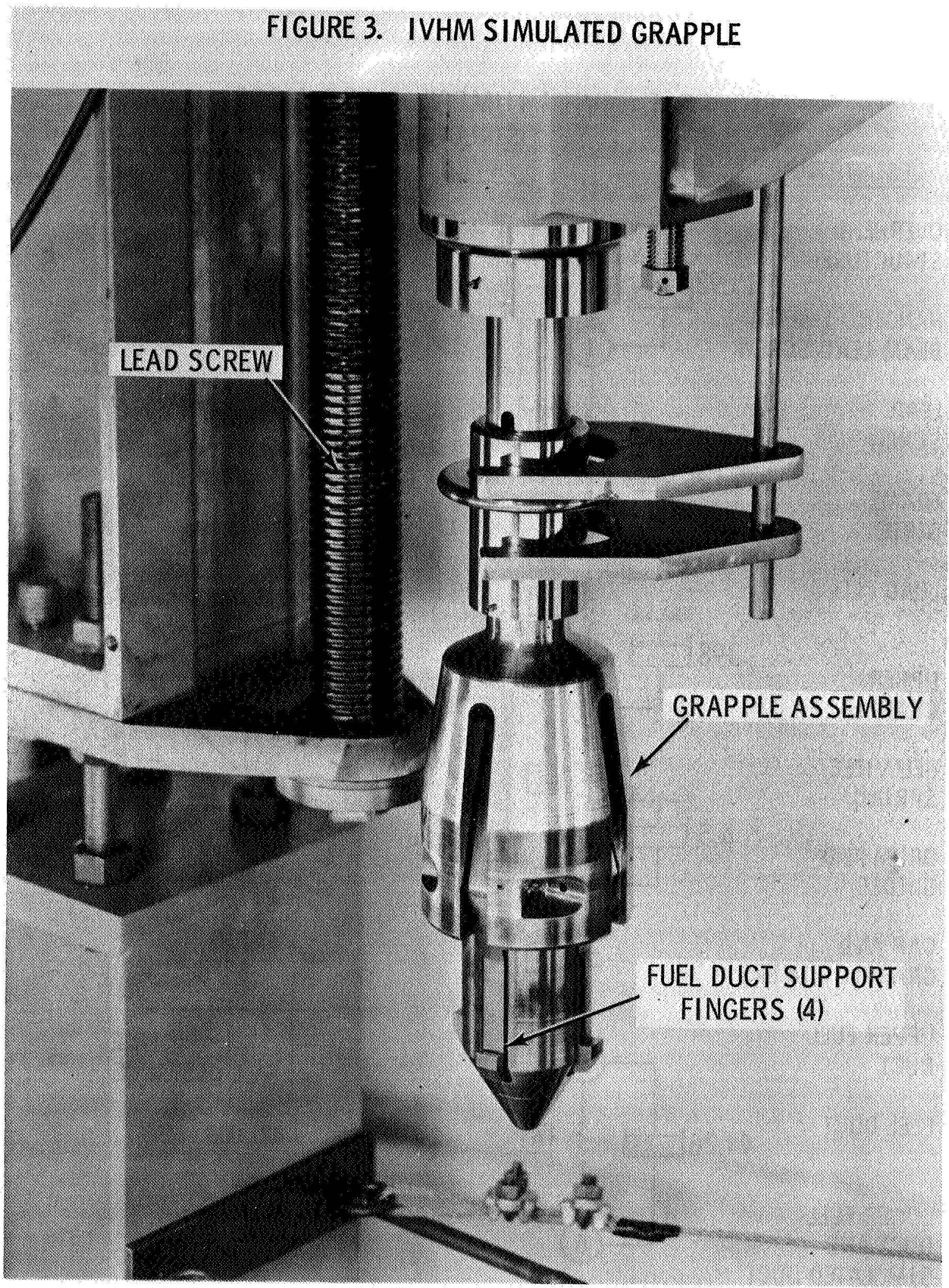


FIGURE 4. IVHM LUMPED -MASS MODEL

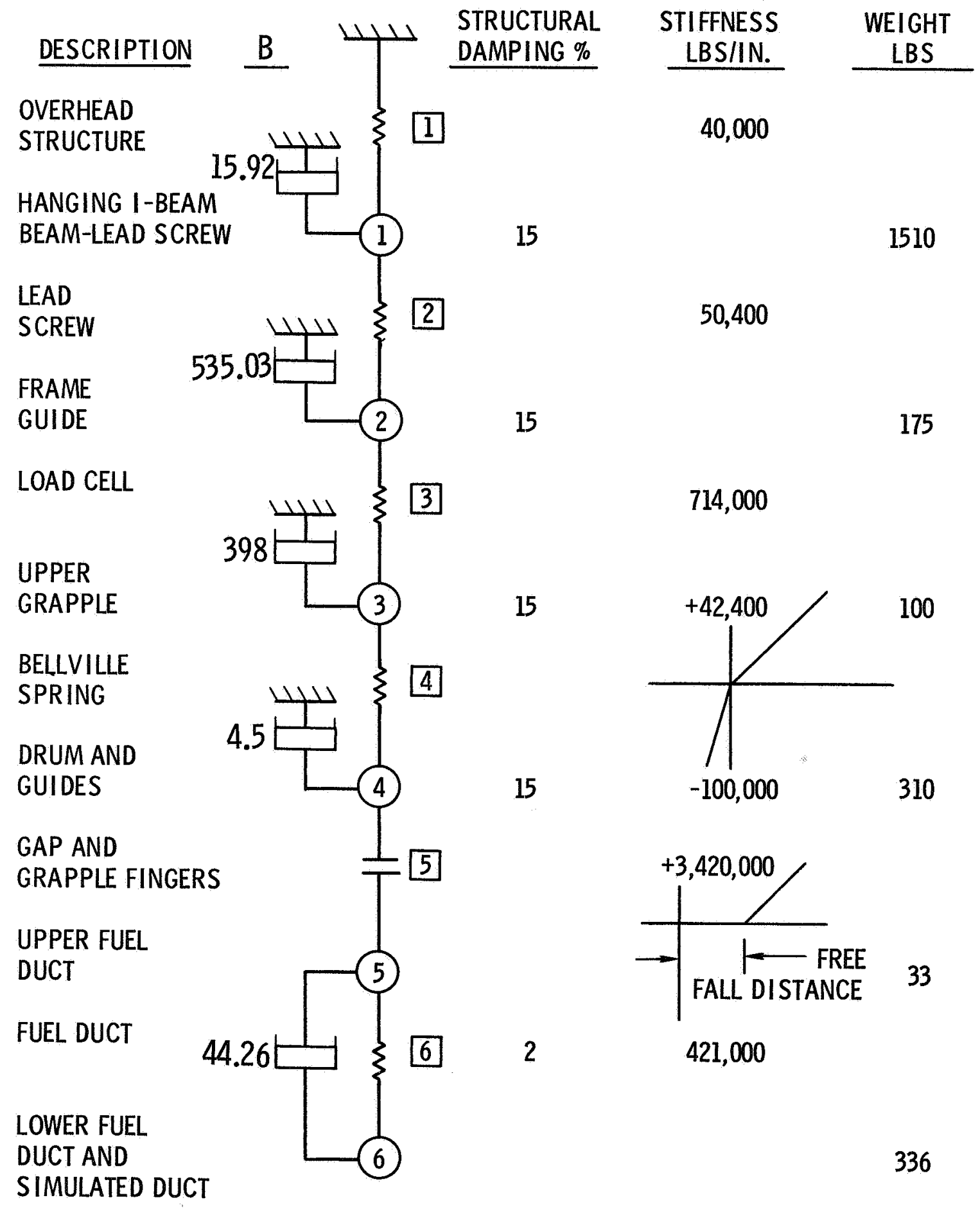




\title{
FIGURE 5. NASTRAN COMPUTER INPUT DATA
}

\author{
$\begin{array}{lll}\text { NASTRAN EXECUTIVE CONTROL DECK } & 72 & \text { PAGE } 1\end{array}$
}

ID GRAPPLE, RUN 102

APP DISPLACEMENT

SOL $\quad 9,0$

TIME $\quad 15$

DIAG $2,3,5,6,9,13$

CEND

IVHM GRAPPLE IMPACT

NONLINEAR BELLVILLE SPRING - 2 PERCENT STRUCTURAL DAMPING

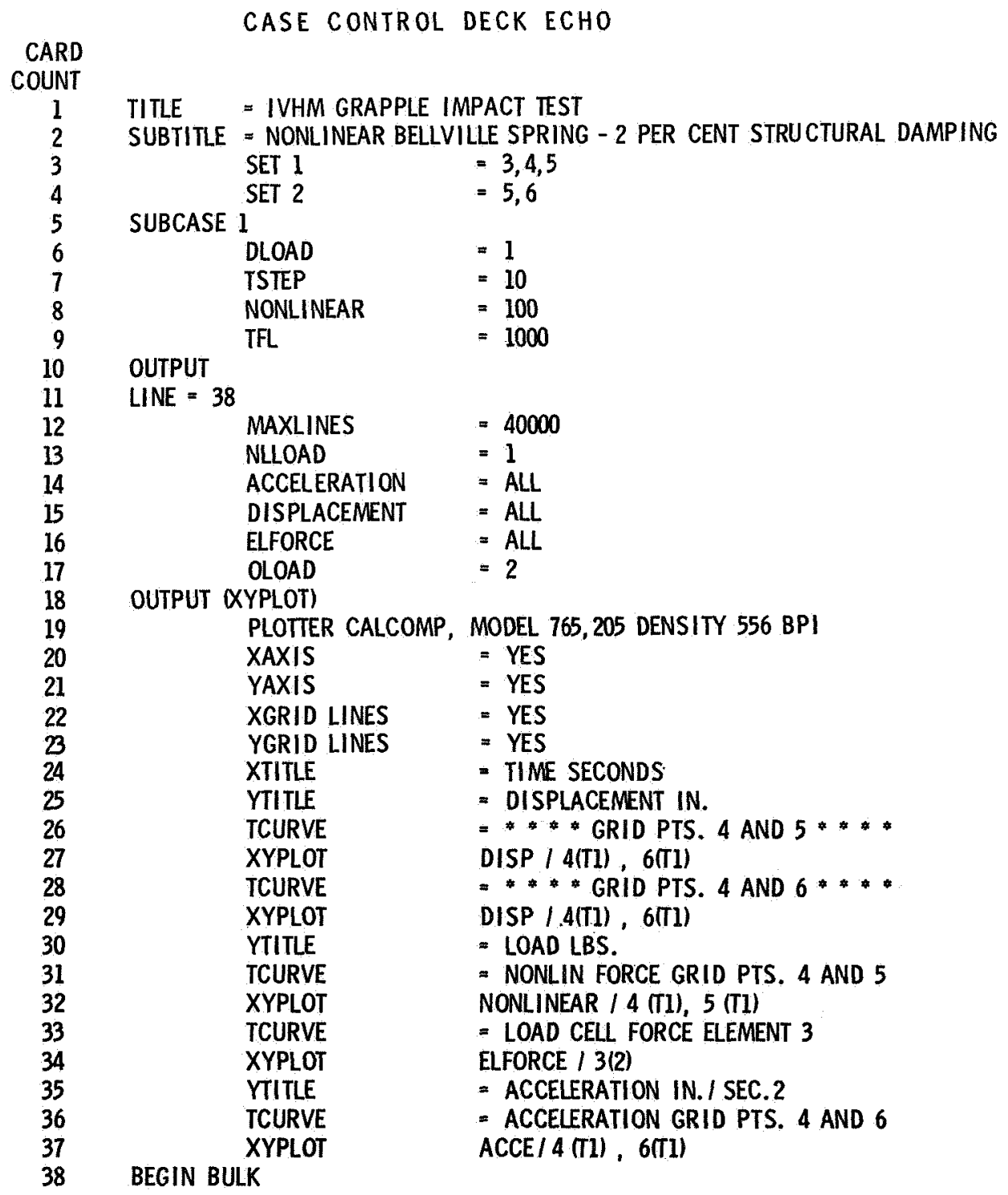




\section{FIGURE 5. (cont.) NASTRAN COMPUTER INPUT DATA}

IVHM GRAPPLE IMPACT TEST

NONLINEAR BELLVILLE SPRING - 2 PERCENT STRUCTURAL DAMPING

72

PAGE 2

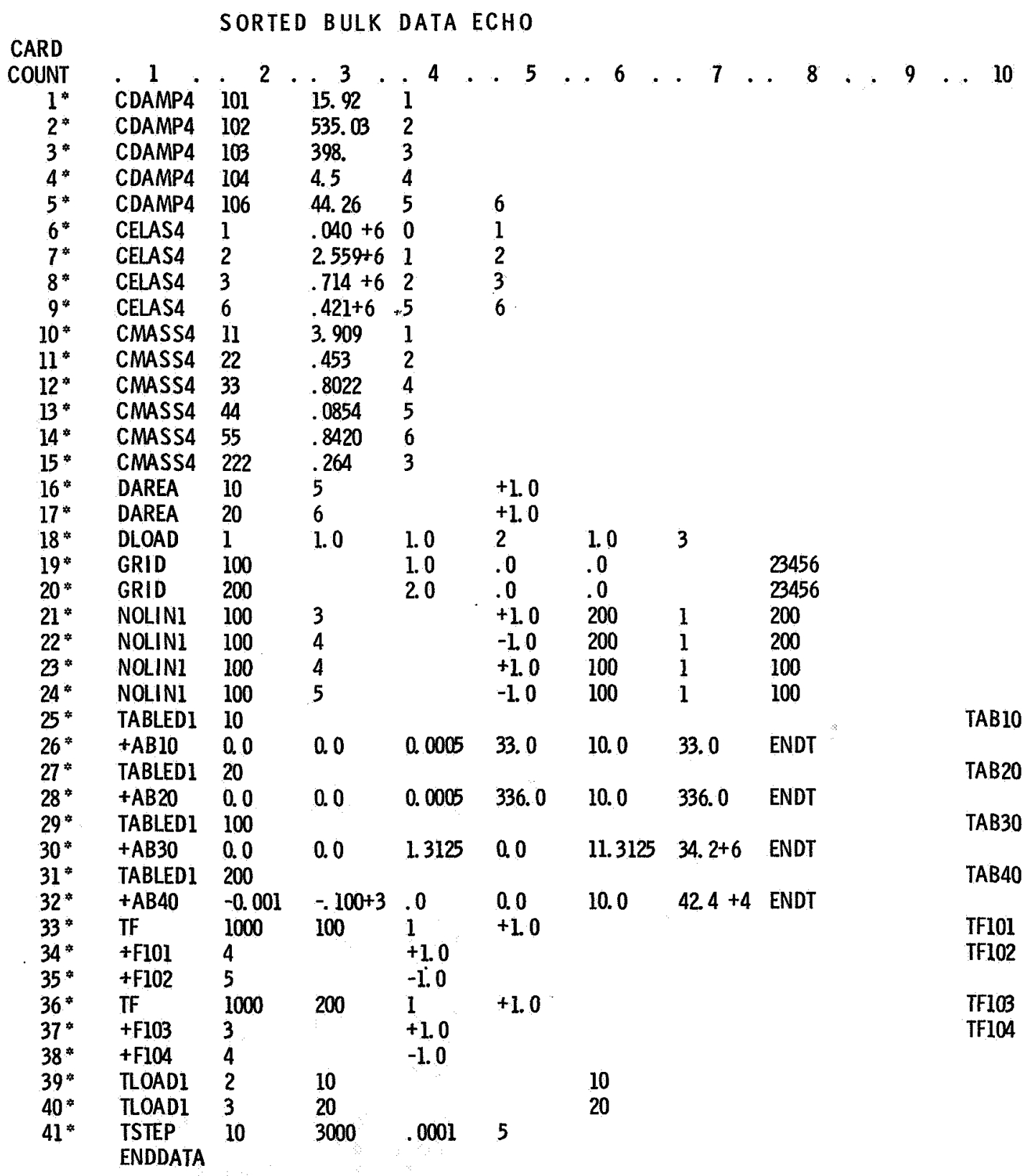


FIGURE 6. EXPERIMENTAL RESULTS - 1 5/16 FREE FALL - TEST N0.19.5.3
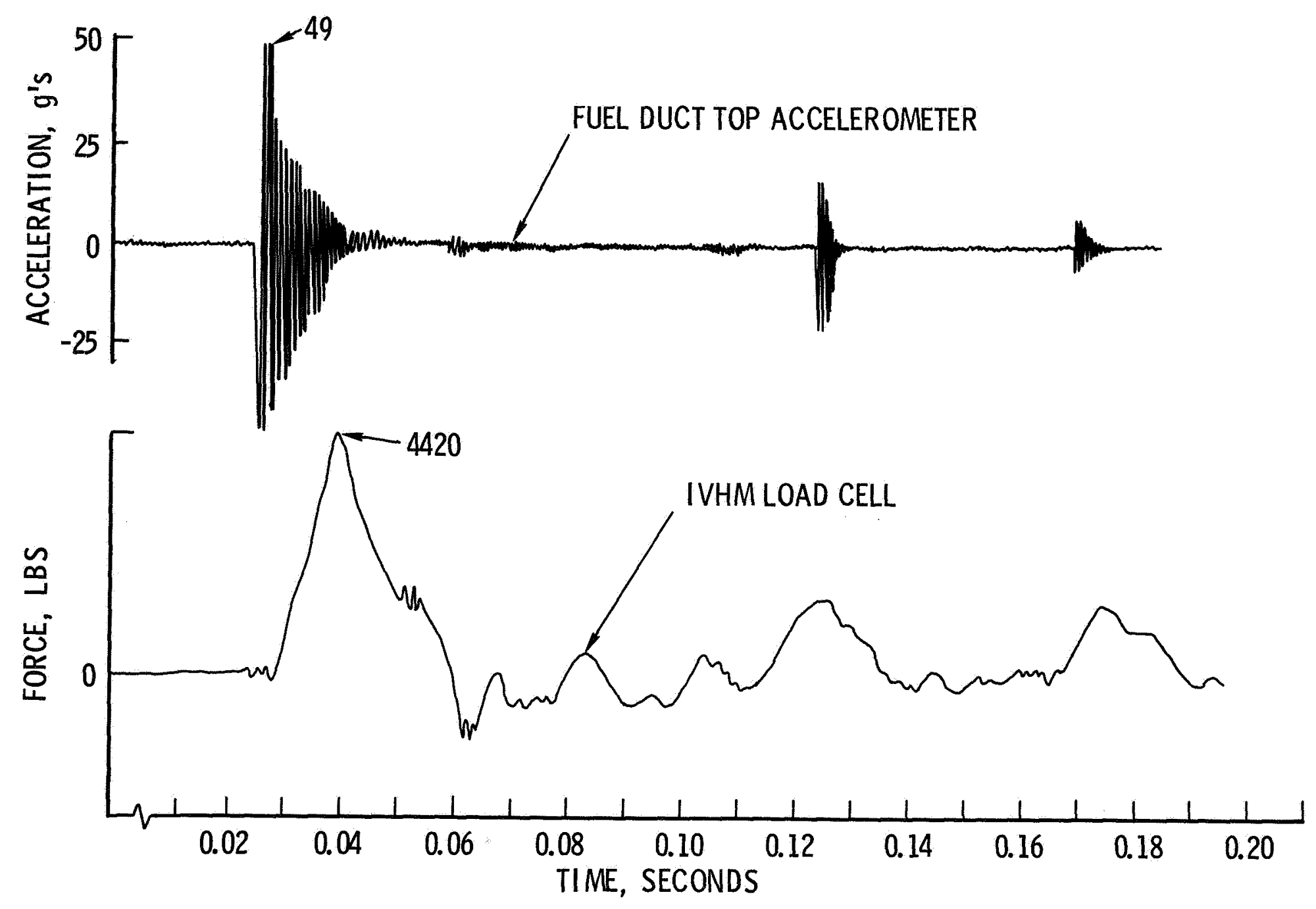
FIGURE 7. GRAPPLE AND FUEL DUCT DISPLACEMENTS - 15/16 IN. FREE FALL

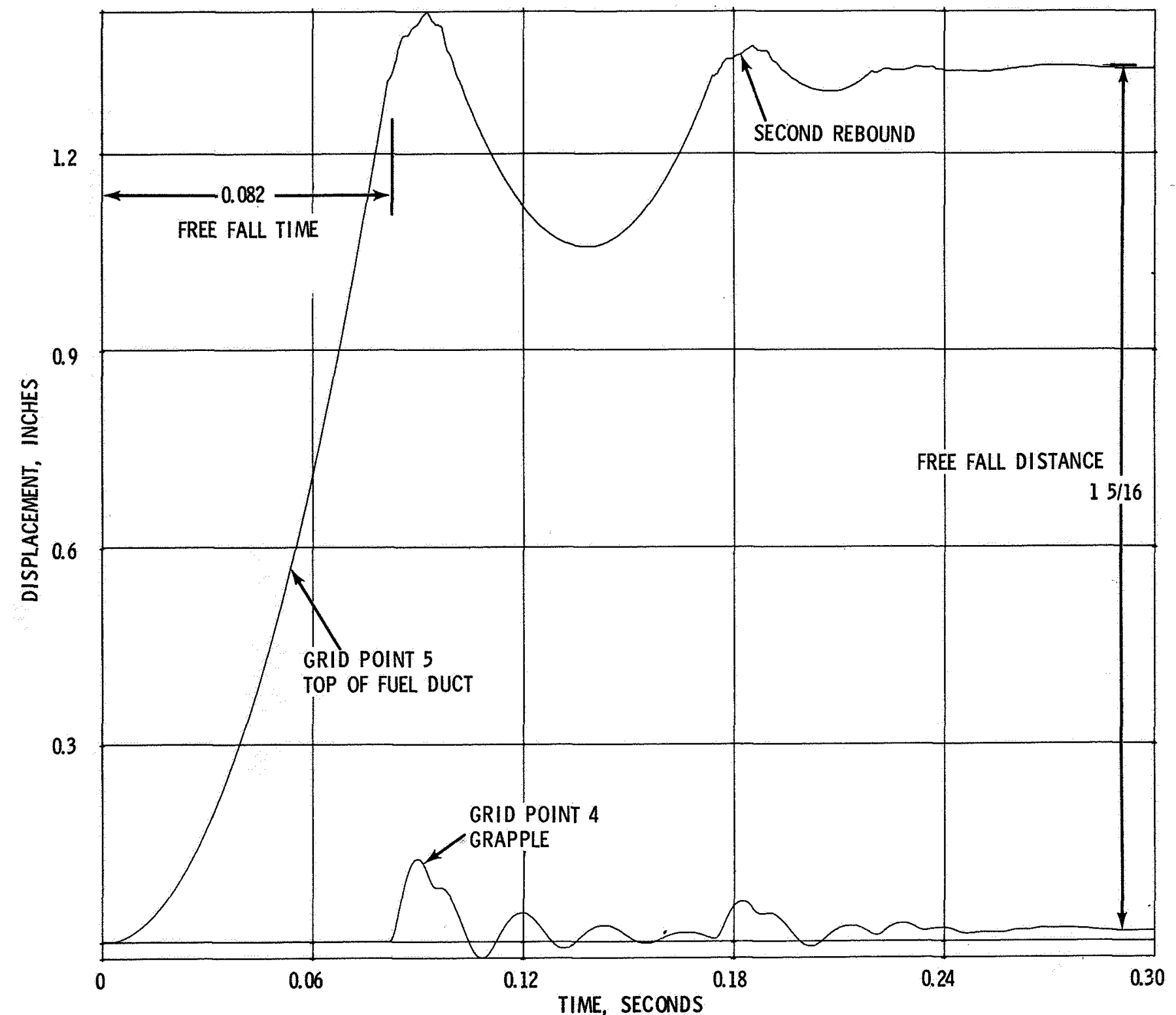


FIGURE 8. LOAD CELL FORCE - 1 5/16 IN. FREE FALL

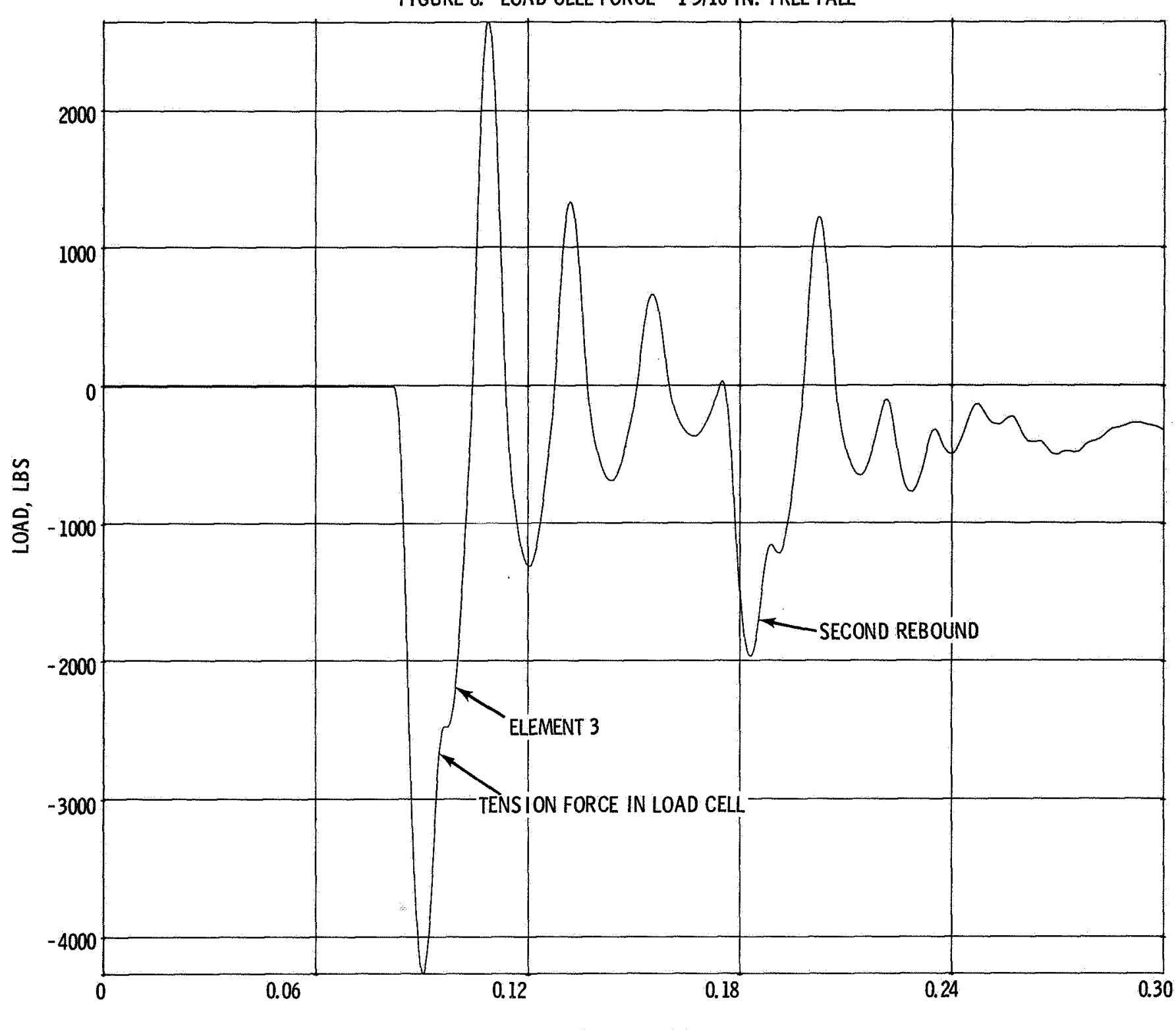

TIME, SECONDS 
FIGURE 9. GRAPPLE AND FUEL DUCT ACCELERATIONS - 15/16 IN. FREE FALL

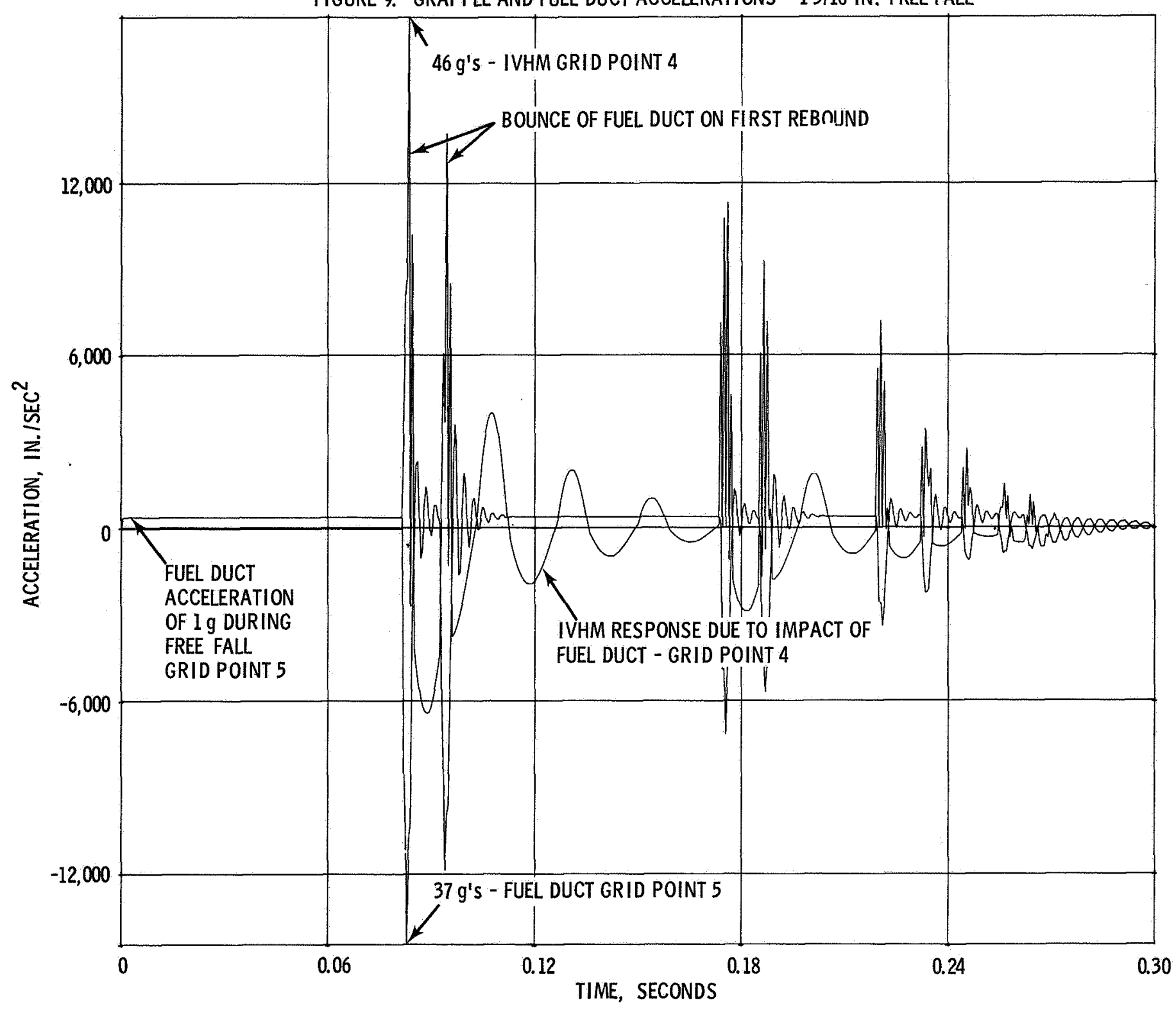


FIGURE 10. GRAPPLE AND FUEL DUCT DISPLACEMENTS - $13 / 8$ IN. FREE FALL $-1,000$ LB PRELOAD

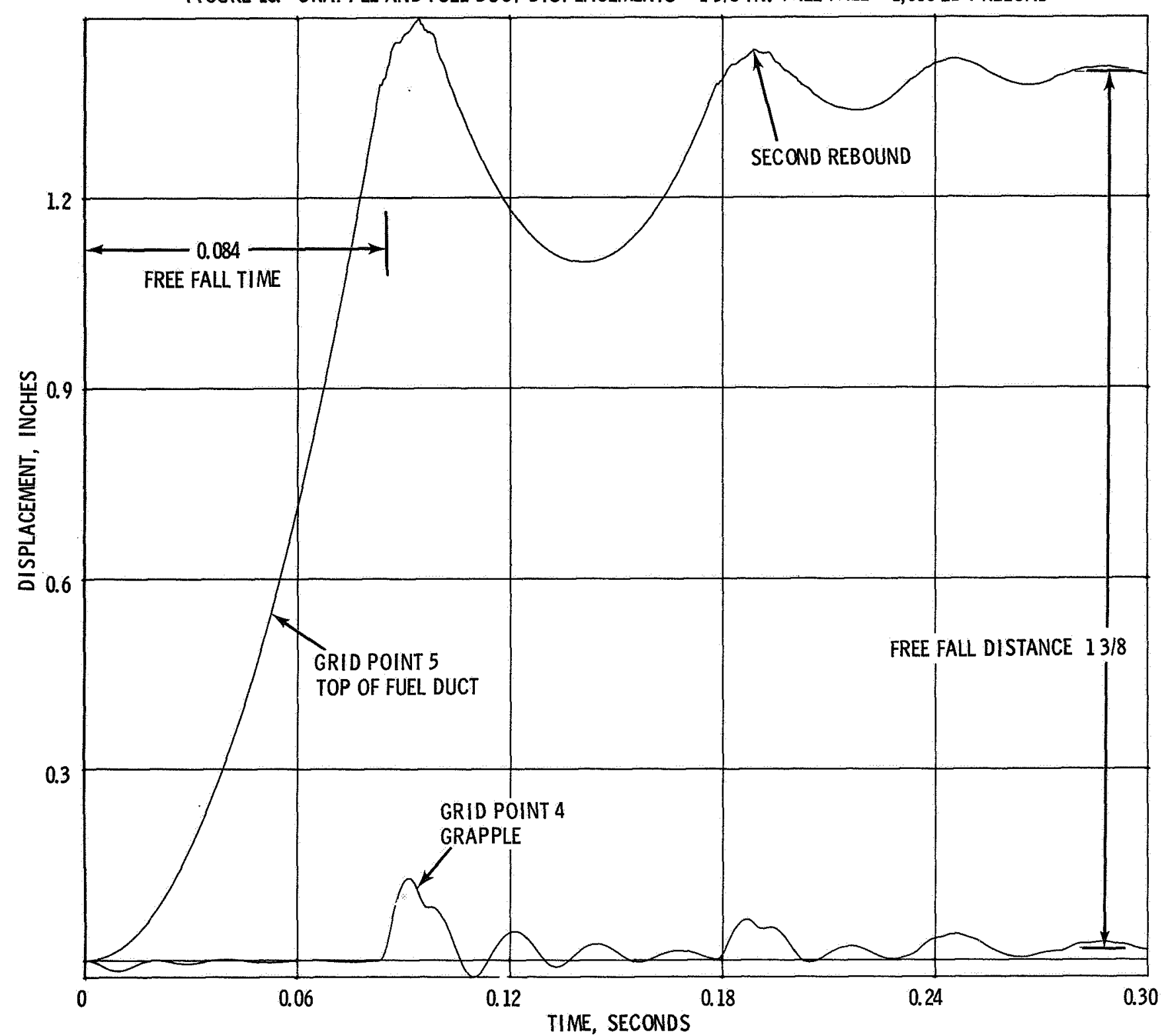


능

FIGURE 11. LOAD CELL FORCE - $13 / 8$ IN. FREE FALL - 1,000 LB PRELOAD

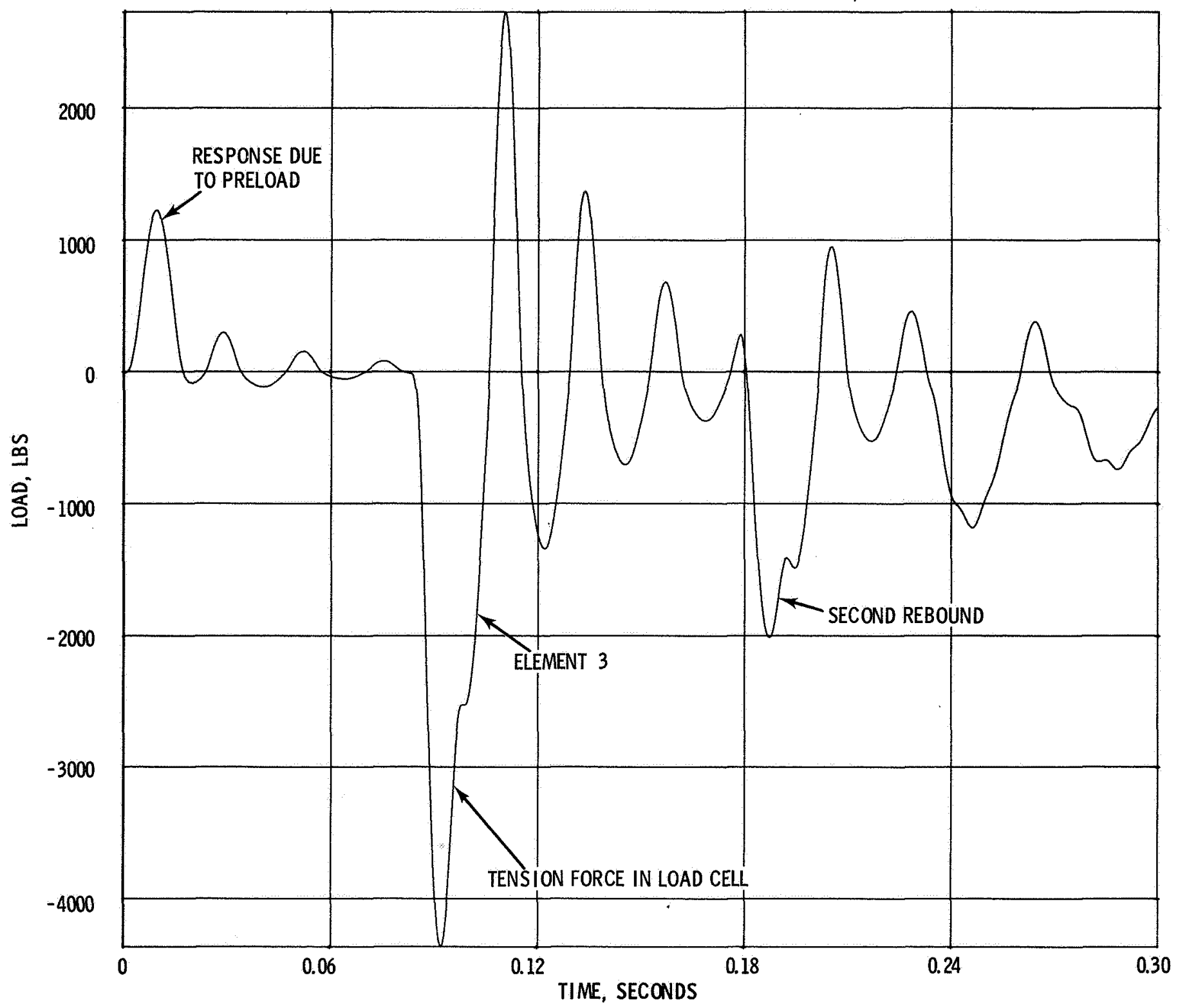




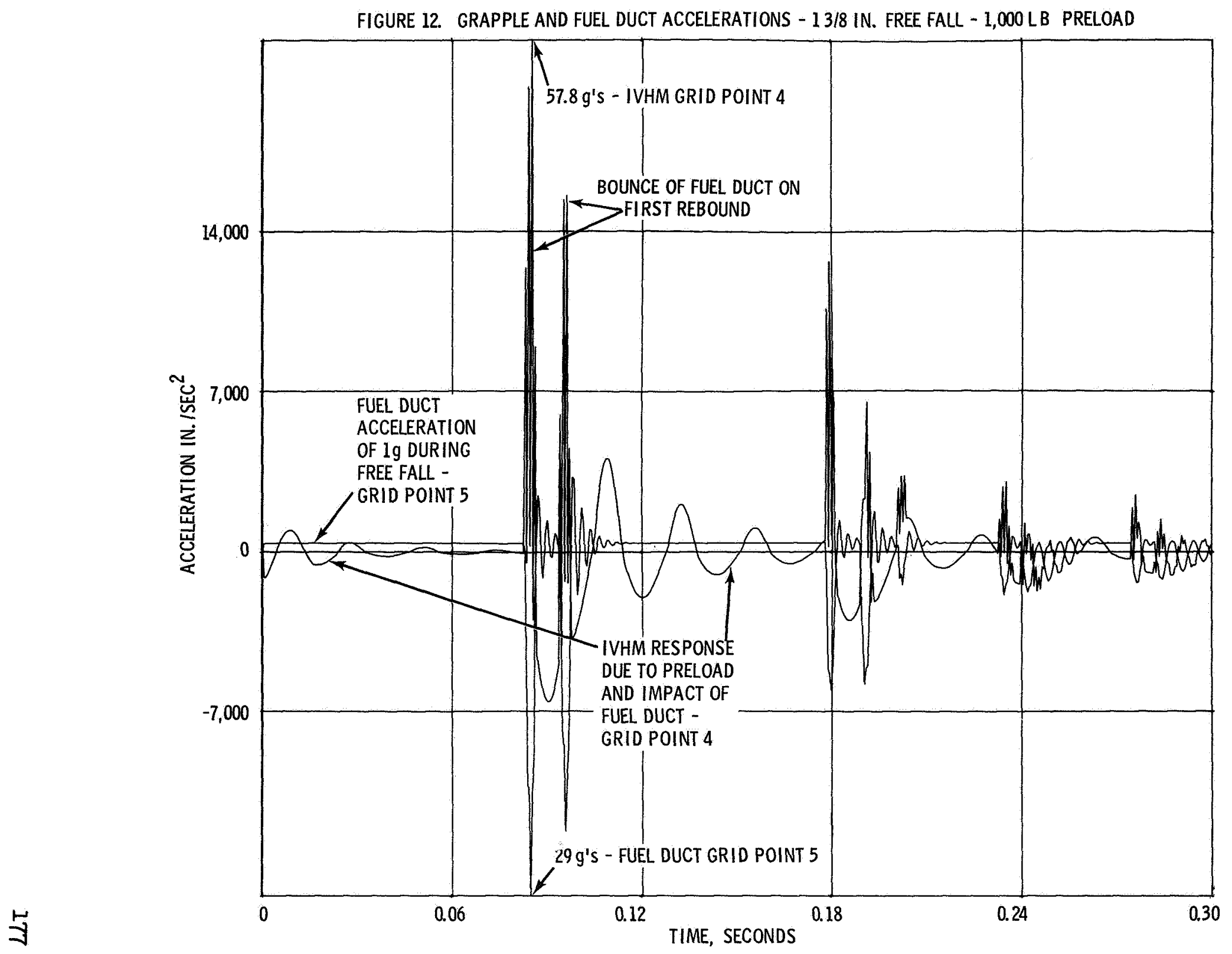


FIGURE 13. COMPARISON OF PEAK VALUES FROM EXPERIMENTAL AND ANALYTICAL RESULTS

\begin{tabular}{|c|c|c|c|c|}
\hline CONDITION & $\begin{array}{l}\text { LOAD } \\
\text { CELL } \\
\text { LBS }\end{array}$ & $\begin{array}{c}\text { ELEMENT } \\
\text { NO. } 3 \\
\text { LBS } \\
\end{array}$ & $\begin{array}{c}\text { ACCELEROMETER } \\
\text { TOP OF DUCT } \\
\text { g's } \\
\end{array}$ & $\begin{array}{l}\text { GRID POIN1 } \\
\text { N0.5 } \\
\text { g's } \\
\end{array}$ \\
\hline $15 / 16$ IN. FREE FALL ${ }^{*}$ & 4,420 & 4,300 & 49 & 37 \\
\hline $13 / 8$ IN. FREE FALL ${ }^{* *}$ & 4,580 & 4,400 & 32 & 29 \\
\hline $\begin{array}{l}* \text { TEST N0.19.5.3 } \\
* * 1.375 \text { IN. FREE FALL } \\
\text { (PRE-LOAD) - TES }\end{array}$ & & INI & CONDITION & 00 LBS \\
\hline
\end{tabular}

